\title{
LAS POTESTADES PÚBLICAS MUNICIPALES EN EL DERECHO MEXICANO.
}

Teresita Rendón Huerta Barrera*

Fecha de recepción: 8 de Septiembre de 2011

Fecha de evaluación 9 de Septiembre de 2011

Fecha de aprobación: 2 de febrero de 2012

\section{SUMARIO}

Introducción. 2.- Estado de derecho y Estado social de derecho. 3.- Los elementos del Estado de derecho. 4.- Las potestades públicas. 5.- La potestad reglamentaria municipal. 6. Conclusiones.

RESUMEN. Dentro del Estado de derecho, cuáles potestades públicas corresponde ejercer al gobierno municipal y cuál es su importancia en la construcción de un verdadero Estado de derecho? Esta es la pregunta sobre la cual se desarrolla el presente trabajo, llegando a la conclusión de que no puede ejercerse potestad pública alguna, al margen del Estado de derecho, por lo cual es imprescindible su definición y delimitación en el orden de gobierno municipal.

Palabras clave: Municipio, potestades públicas, Estado de derecho, facultad reglamentaria de los ayuntamientos.

ABSTRACT. Under the rule of law, which is responsible for exercising public powers to the municipal government and what is its importance in the construction

\footnotetext{
* Doctora en Derecho. Profesora investigadora del Departamento de Derecho de la División de Derecho, Política y Gobierno del campus Guanajuato de la Universidad de Guanajuato.
} 
of a genuine rule of law? This is the question on which this work takes place, concluding that no public authority can be exercised any, outside the rule of law, which is essential to its definition and delimitation of the order of the municipal government.

KEY WORDS: Municipality, public powers, rule of law, regulatory power of municipalities.

\section{1.- Introducción.}

Es importante reencontrar al Municipio en un país que lo ha perdido de vista, ante el quimérico confort y la soñada riqueza prometidas por los tratados de libre comercio firmados por México y la globalización; en un país cuya imagen actual, en el contexto de las naciones, parece desdibujada al ya no contar su glorioso pasado prehispánico y las múltiples manifestaciones del arte y la cultura universales que otrora se produjeron y que siguen produciéndose.

Pensar en la hora presente, qué representa la vida municipal, con sus historia, sus vivencias y sus leyes, es recobrar lo propio, volver a las raíces, es creer que el Municipio es simiente espléndida y fecunda no sólo de una verdadera democracia, sino de convivencia civilizada y pacífica.

No obstante los avances de la ciencia y la tecnología, la carencia de lo más elemental se expande por muchas regiones de nuestro país. Entre todas esas carencias, la consecución de un verdadero Estado de derecho, surge como imperativo inaplazable.

El problema que originó esta investigación, reside en una pregunta: ¿Dentro del Estado de derecho, cuáles potestades públicas corresponde ejercer al gobierno 
municipal y cuál es su importancia en la construcción de un verdadero Estado de derecho? Dado que es un tema escasamente explorado en el Derecho municipal mexicano, no se localiza literatura jurídica al respecto, por lo cual uno de los propósitos del presente trabajo, es contribuir a la formación de una base doctrinaria propia en el contexto nacional. La hipótesis es que no puede ejercerse potestad pública alguna, al margen del Estado de derecho, por lo cual es imprescindible su definición y delimitación en el orden de gobierno municipal. EI método utilizado es el deductivo, resultando de señalada importancia mencionar que este tema es un elemento sine qua non de la seguridad jurídica.

No basta decir que todo Estado, por su connaturalidad con el Derecho, es Estado de derecho. Esta fórmula implica más bien un compromiso fundamental: el de que el poder político para mantener, en condiciones normales, el equilibrio entre la libertad y el orden normativo, se someta a éste y no traspase sus mandatos. Y el de que el propio orden jurídico encarne satisfactoriamente, en cada época, los valores de justicia y seguridad en que reposa la comunidad humana a la que se pretenden servir.

La evolución misma de la sociedad, demanda un enorme impulso a la cultura cívica en múltiples aspectos, sobre todo en la promoción del Estado de derecho y de la legalidad. Este es un reto sin precedentes que habrá de enfrentarse a partir de la educación y el respeto a la dignidad y a los derechos fundamentales de toda persona.

La falta de atención a este aspecto, durante largos periodos de nuestra historia, se traduce hoy con frecuencia, en la incapacidad de valorar, aprovechar y defender nuestras instituciones. 
De lo anterior se desprende la dimensión y la enorme trascendencia, de pasar de la retórica a los hechos, para construir un real Estado de derecho en el ámbito municipal, a partir del correcto ejercicio de las potestades administrativas que corresponden a este ámbito de gobierno.

2. Estado de derecho y Estado social y democrático de derecho.

A partir de la tercera década del siglo pasado, la expresión "Estado de derecho" adquiere una connotación precisa. Fue el tratadista alemán Robert Von Mohl quien aplicó la locución "Rechsstaat", para significar la regulación, sometimiento y control de la colectividad y del poder público, de sus órganos y funciones por medio del Derecho.

La noción de Estado de derecho se contrapone a la idea de un estado anárquico, arbitrario, omnímodo o totalitario. Así, por Estado de derecho (Rule of law para los juristas angloamericanos) se entiende, básicamente, aquel Estado cuyos diversos órganos e individuos miembros, se encuentran regidos por el Derecho y sometidos al mismo; esto es, Estado de derecho alude a aquel Estado cuyo poder y actividad están regulados y controlados por el Derecho. (Diccionario 1982)

El Estado contemporáneo es concebido en los sistemas jurídicos de occidente, como un Estado sometido al Derecho. La Constitución es por una parte, la forma en que se manifiesta la soberanía nacional y por otra, el fundamento jurídico de todas las actividades de los órganos estatales, así como de las actividades facultadas y protegidas de los particulares. (Villoro Toranzo, 1975)

No es posible partir de un Estado sin Derecho, ni de la identificación del Estado con el Derecho, como lo pretendía Hans Kelsen (1977), al afirmar que "El Estado es la personificación del orden jurídico". Más bien debemos hablar de una continua 
interacción de ambos conceptos, que viven en una constante "tensión dialéctica" que se resuelve por una síntesis de colaboración y armonía. (González Uribe, 1982)

"El problema de la relación del Derecho y del Estado, se halla íntimamente ligado al problema de soberanía y al fundamento de la misma. Al abordar el problema no conviene perder de vista el carácter dialéctico de esa relación, ni la característica del poder como formador del Derecho". (Pedroso, 1950)

El Derecho es connatural al Estado. Es la atmósfera misma en que el Estado vive y se desarrolla. $Y$ es también el principio fundamental de su legitimidad y justificación. Por esa razón todo Estado de nuestros días, deber ser un Estado de derecho.

Al respecto, Manuel Pedroso elaboró el las posibles relaciones entre el Estado (E) y el Derecho (D), que presento en el siguiente esquema:

(E)-(D) ¿Cómo ligarlos? ¿Qué relación existe entre ellos? Tomándolos en forma aislada, no existe uno sin el otro: el Derecho sin el Estado no es nada; el Estado sin el Derecho tampoco es nada. El Estado sin el Derecho es un simple fenómeno de fuerza.

(E)

sin Un simple fenómeno de fuerza.

(D)

La proposición contraria, el Derecho sin el Estado, es una mera idealidad normativa, una norma sin efectividad

(D)

sin Una mera idealidad normativa, norma sin efectividad. 
(E) La teoría de Kelsen, Estado igual a Derecho, da como resultante la confusión de una parte substancial (el Derecho) con el todo (el Estado).

La posición correcta es la siguiente: Estado con Derecho, lo que equivale al "Estado de Derecho" moderno.

(E)

con $\quad$ "Estado de Derecho" moderno.

(D)

De lo anterior se colige que Estado y Derecho, son conceptos y realidades que se implican mutuamente y que en nuestros días, han llegado a tener un vínculo indestructible a través de la noción "Estado de derecho". Avance singular de la civilización, que ha ido evolucionando en el presente siglo para incorporar a dicha fórmula, la idea de lo social, de lo democrático y lo garantista, dando por resultado el "Estado constitucional, social y democrático de derecho", cuya pretensión inicial fue atemperar las fallas derivadas del individualismo liberal y avanzar en la conformación de un Estado garantista.

Así, el Estado constitucional, social y democrático de derecho, reúne los elementos de juridicidad, añadiendo como características la tutela a los derechos sociales, la intervención en materia económica, política, social y cultural, así como la búsqueda de la justicia social y la protección a los derechos humanos.

A pesar de las variantes introducidas, la concepción del Estado social de derecho conserva, en buena medida, las características y exigencias señaladas anteriormente como propias del Estado de derecho: en particular, la sujeción de los órganos estatales al Derecho; pero, simultáneamente, el que las leyes emanen de un órgano popular representativo, bajo procedimientos previstos por otras normas jurídicas; la distribución y control del ejercicio del poder político; la legalidad de la administración y un control judicial suficiente; la garantía de los 
derechos y libertades fundamentales, entre otros elementos. Para afirmar que se está en presencia de un "Estado social de Derecho se requiere que el mismo satisfaga, además de sus objetivos sociales, las exigencias que se han considerado propias del Estado de derecho". (González Uribe, 1982)

El concepto clásico ha evolucionado de tal forma, que hoy no se limita sólo al mantenimiento de un orden jurídico, sino que busca el logro de fines sociales, la consolidación de la democracia y la protección de los derechos fundamentales.

3. Los elementos del estado de derecho.

Como elementos fundamentales del Estado de derecho es posible destacar los siguientes:

1) El reconocimiento de la superioridad y preeminencia de los valores éticos del Derecho.

2) La voluntad de asumir soberanamente como propios dichos valores.

3) Un conjunto de reglas que permitan hacer realidad tales valores dentro de una comunidad determinada.

4) Esas reglas deben derivar de la Constitución Política de cada país y en su conjunto forman el Derecho positivo.

5) Los principios fundamentales que deben cumplirse y de los cuales debe partir la formulación de tales reglas en un Estado de derecho son:

- La existencia de una Constitución escrita y rígida, que determine con claridad cuáles son los órganos del Estado. 
- La delimitación legal de las correspondientes atribuciones y competencias -las potestades públicas-.

- La supremacía constitucional sobre cualquier otra norma.

- La congruencia y sujeción de todo el orden jurídico a la Ley Fundamental, lo que implica que a ella se ajusten todas las leyes, reglamentos, decretos y demás disposiciones de carácter general.

- La determinación constitucional de una serie de garantías para toda persona, garantías que no puedan ser violadas por ninguna ley o autoridad.

- El reconocimiento del principio de legalidad, que se traduce en la prohibición a las autoridades para actuar si no hay alguna ley o norma de carácter general que lo prevea.

- El respeto irrestricto a la garantía de audiencia, que impide privar a alguien de sus derechos, sin previo juicio en que se le conceda la oportunidad de defenderse.

- El equilibrio del poder público y la división de funciones, con un sistema no sólo de frenos y contrapesos para evitar abusos y extralimitaciones, sino además, con fórmulas de colaboración.

- El establecimiento de mecanismos de participación de la ciudadanía, en los asuntos públicos, mediante las instituciones correspondientes -referéndum, plebiscito, iniciativa popular, acción popular, entre otras- y una 
organización electoral confiable, para el logro de un gobierno auténticamente representativo.

- La pluralidad, veracidad y libre competencia de los medios de información; tales como radio, Internet, televisión, prensa, etc., que permitan no sólo el conocimiento de las actividades gubernamentales, sino su vigilancia y seguimiento.

- El establecimiento - tanto en la Constitución como en las demás leyes- de un sistema de impugnaciones; esto es juicios y recursos, tanto jurisdiccionales como administrativos.

Al hacer alusión al tercer elemento del Estado de derecho contemporáneo, se sugiere ya la importancia de las reglas del Derecho, mismas que tienen seguramente un origen tan remoto como el Derecho mismo, pero es en una etapa histórica de fecunda creación, cuando las especulaciones filosóficas y jurídicas de los antiguos llegaron a formularlas tal como algunas de ellas llegan a nuestros días y tienen aún vigencia en el Derecho contemporáneo, aunque los fundamentos con que ahora se les pueda invocar son distintos a aquellos con que las invocaban los juristas de la antigüedad, los de las Edad Media y aún los juristas de la Edad Moderna y Contemporánea "hasta una fecha no lejana y que no puede ubicarse con precisión, pero que corresponde a las últimas décadas, en que se precisan y afianzan las nuevas doctrinas sobre los problemas fundamentales del Derecho". (Enciclopedia, 1982)

Ciertas corrientes contemporáneas parten de la idea de que no hay lagunas en la ley, y de que para aplicar el Derecho positivo no se requiere acudir a las fuentes supletorias del Derecho, en virtud de que es en el ordenamiento jurídico, donde 
debe encontrarse la solución a todos los casos que plantea la realidad, lo que sin duda pone de manifiesto la necesidad de replantear la validez de esa afirmación.

Tales asertos adquieren una enorme dimensión en países que como el nuestro, tienen fincada su tradición jurídica en el Derecho escrito y que deben basar la actuación de sus órganos, en el principio de legalidad.

4. Las potestades públicas.

Bajo estas premisas, el tema de las potestades públicas, como contenido de la competencia municipal, adquiere una especial relevancia.

Las potestades públicas son una derivación de la supremacía estatal, presuponen relaciones jurídicas, son una consecuencia del Estado de derecho y tienen los siguientes caracteres:

1) Son inalienables e intransferibles de un ente a otro, pudiéndose en ocasiones, delegar su ejercicio pero no transferir su titularidad.

2) Son irrenunciables. Puede ocurrir que el titular pueda ejercerlas o no, pero la pérdida no depende de su voluntad. Podrá renunciarlas en algunos casos y bajo condiciones que determinan ciertas atribuciones particulares, pero de ninguna manera puede renunciar a su competencia general.

3) Son imprescriptibles. No pueden adquirirse o perderse por el transcurso del tiempo.

4) Son inmodificables. En virtud de que su ejercicio debe apegarse a la norma que les ha dado origen, sin que jurídicamente pueda variarse su contenido ni finalidad. 
5) Son expresas. Lo que implica que siempre deben estar previstas en el ordenamiento jurídico, por el principio de legalidad.

6) Son específicas. La norma prevé un poder trazado, limitado, concreto; tanto en las potestades regladas, respecto a las cuales el legislador define exhaustivamente sus elementos, como en las potestades discrecionales, en las que si bien se deja un margen de decisión, debe establecerse su extensión, la atribución al órgano y el fin. No pueden conferirse globalmente.

El administrativista argentino Manuel María Diez, (1963) las clasifica así:

De mando

$\begin{array}{cc}\text { Clases de potestades } & \text { Reglamentaria } \\ \text { administrativas } & \text { Sancionadora } \\ & \text { Jurisdiccional }\end{array}$

La potestad de mando, llamada también potestad imperativa, es la facultad de dictar órdenes y obligar a su cumplimiento. Se compone de cuatro elementos: 1) Una voluntad plusvalente o elemento psicológico; 2) Un sujeto activo o elemento físico activo; 3) Un sujeto pasivo o elemento físico pasivo; y 4) Determinadas obligaciones dirigidas a un fin: resolver un conflicto de intereses o elemento económico:

Discrecional

La potestad de mando puede ser: Reglada

Soberana

Derivada 
La potestad reglamentaria, es la facultad de crear normas jurídicas de carácter general e impersonal, que legalmente se atribuye a los Ayuntamientos.

La potestad sancionadora, es la facultad de imponer castigos administrativos a los infractores de las normas para asegurar indirectamente su eficacia.

Disciplinaria. Se ejerce en el ámbito interno de la administración pública municipal, sobre los servidores, por acciones u omisiones que cometan en, o con motivo del desempeño de sus cargos.

La potestad sancionadora puede ser:

Correctiva. Se ejerce al exterior de la administración pública municipal, y abarca a todos los gobernados.

Disciplinaria. Se ejerce al interior de la administración pública municipal, por actos $u$ omisiones de los servidores municipales.

La potestad jurisdiccional, es la facultad de llevar a cabo el control de la legalidad de los actos de la administración pública, tanto en sede administrativa por medio de recursos, como ante órganos materialmente jurisdiccionales, como son en nuestro país, los Tribunales de lo Contencioso Administrativo.

La potestad de ejecución, es reconocida como independiente de las anteriores, sólo por un grupo de autores, que se refieren a la misma, como la potestad productora de la serie de actos que realiza la administración en ejercicio concreto de su obra y que comprende los hechos que puede realizar en el ejercicio de sus funciones, el cumplimiento de lo legislado y de lo que reglamentado, la realización de lo que mande y sancione dentro de su esfera. 
Representación

Fe pública

Registro

Investigación

Clasificación de datos generales

Instrucción

La potestad ejecutiva

Dirección

comprende actos de:

Impulso

Vigilancia

Inspección y comprobación

Fuerza

Tutela

Facultativos

Técnicos

Gestión económica

Gracia y dispensa

Las potestades públicas en el ámbito municipal, deben ejercerse siempre dentro de un contexto jurídico. Dentro de las mencionadas, sin duda la reglamentaria, dentro del Estado de derecho, tiene una gran importancia, porque se traduce en la creación de normas jurídicas.

5. La potestad reglamentaria municipal.

El artículo 115 de la Constitución Política de los Estados Unidos Mexicanos, en su fracción II, párrafo segundo, dice: "Los ayuntamientos tendrán facultades para aprobar, de acuerdo con las leyes en materia municipal que deberán expedir las legislaturas de los Estados, los bandos de policía y gobierno, los reglamentos, 
circulares y disposiciones administrativas de observancia general dentro de sus respectivas jurisdicciones, que organicen la administración pública municipal, regulen las materias, procedimientos, funciones y servicios públicos de su competencia y aseguren la participación ciudadana y vecinal."

Los reglamentos suponen la existencia previa de una ley, a fin de que su cumplimiento se realice puntualmente. La potestad reglamentaria municipal, proviene de la Constitución misma, que se la confiere directamente a los ayuntamientos. Su magnitud dentro de la jerarquía normativa, no ha sido suficientemente apreciada. Y esto tal vez sea sólo un reflejo de la escasa o nula importancia que suelen concederle los miembros de los ayuntamientos, en ocasiones por la falta de una preparación idónea, en otras, porque su dimensión dentro del orden jurídico, se pierde en la rutina de una administración casi doméstica, que frecuentemente se basa en la costumbre y en la improvisación.

En términos del Estado de derecho, no sólo el estudio, conformación y expedición de reglamentos de calidad -en contenido y forma-, producirá el cambio radical en favor del Municipio mexicano, se requerirá el diseño y ejecución de un sistema capaz de hacerlos cumplir, dentro del orden y del respeto a los derechos fundamentales de la persona

Por lo anterior, el Estado de derecho en el ámbito municipal, es no sólo expresión de los postulados constitucionales, sino forma para alcanzar la paz social, a través de un justo equilibrio en el ejercicio de las potestades públicas y la esfera jurídica de los administrados.

\section{Conclusiones:}


1. No basta decir que todo Estado, por su connaturalidad con el Derecho, es Estado de derecho. Esta fórmula implica más bien un compromiso fundamental: el de que el poder político para mantener, en condiciones normales, el equilibrio entre la libertad y el orden normativo, se someta a éste y no traspase sus mandatos.

2. La noción de Estado de derecho se contrapone a la idea de anarquía, arbitrariedad y totalitarismo.

3. Deberá construirse un real Estado de derecho en el ámbito municipal, a partir del correcto ejercicio de las potestades administrativas, que corresponden a este ámbito de gobierno.

4. El Estado constitucional, social y democrático de derecho, además de reunir los elementos de juridicidad, añade la tutela a los derechos sociales, la intervención en materia económica, política, social y cultural, así como la búsqueda de la justicia social y la protección a los derechos humanos.

5. No puede ejercerse potestad pública alguna, al margen del Estado de derecho, por lo cual es imprescindible su definición y delimitación en el orden de gobierno municipal, como elemento sine qua non de la seguridad jurídica.

6. Los reglamentos municipales suponen la existencia previa de una ley, a fin de que su cumplimiento se realice puntualmente. La potestad reglamentaria municipal, proviene de la Constitución, que se la confiere a los ayuntamientos. Su magnitud dentro de la jerarquía normativa, no ha sido suficientemente apreciada. Y esto tal vez sea sólo un reflejo de la escasa o nula importancia que suelen concederle los miembros de los ayuntamientos. 


\section{Referencias Bibliográficas:}

1. Diccionario Jurídico Mexicano. Instituto de Investigaciones jurídicas de la Universidad Nacional Autónoma de México. Ed. Porrúa, tomo D.H. México 1982, p. 328 y ss.

2 Enciclopedia jurídica Omeba, tomo XXIV. Ed. Bibliográfica (Driskill), Buenos Aires, 1982, p. 528

3. GONZÁLEZ URIBE, Héctor. Teoría política. Ed. Porrúa, México, 1982, 3aㅗ Edición, p. 222.

4. KELSEN, Hans. Teoría pura del Derecho. (Introducción a la Ciencia del Derecho). Editorial Universitaria de Buenos Aires, Buenos Aires, 1977.

5. PEDROSO, Manuel. "Relación entre Derecho y Estado y la idea de soberanía". En Revista de la Escuela Nacional de Jurisprudencia. UNAM, tomo XII, núm. 46, México, 1950, p. 123.

6. VILLORO TORANZO, Miguel. Derecho público y derecho privado. Ed. Jus. México, 1975. 